\title{
A frequency questionnaire to estimate free-living physical activity among Tunisian preadolescent and adolescent children
}

\author{
Houda Ben Gharbia ${ }^{1}$, Agnès Gartner ${ }^{2}$, Pierre Traissac ${ }^{2}$, Francis Delpeuch ${ }^{2}$, \\ Bernard Maire ${ }^{2}$ and Jalila El Ati ${ }^{1, *}$ \\ 'Department of Studies and Planning, National Institute of Nutrition and Food Technology (INNTA), 11 rue Jebel \\ Lakhdar, Bab Saadoun, 1007 Tunis, Tunisia: ${ }^{2}$ Institut de Recherche pour le Développement (IRD), UMR 204 \\ NUTRIPASS, IRD-UM2-UM1, Montpellier, France
}

Submitted 21 December 2012: Final revision received 31 August 2013: Accepted 4 September 2013: First published online 14 October 2013

\begin{abstract}
Objective: To develop a child- and adolescent-appropriate physical activity frequency questionnaire (PAFQ) in Tunisia, North Africa.

Design: A PAFQ was developed from a physical activity (PA) inventory that comprised major activity components (at home, preparing meals, school time, transport, non-sport leisure, sports, prayer and sleeping time). Then, type and duration of each activity undertaken during the past week were estimated. Total energy expenditure (TEE) estimated by the PAFQ was compared with data derived from two criterion methods: heart-rate monitoring (HRM) and a $24 \mathrm{~h} \mathrm{PA}$ recall ( $24 \mathrm{~h}-\mathrm{R})$, both collected during a $3 \mathrm{~d}$ period including one weekday and two weekend days.

Setting: Two elementary schools and two high schools of the most developed and urbanized area, Greater Tunis.

Subjects: One hundred and forty-two volunteer children and adolescents aged 10-19 years.

Results: The PAFQ strongly was correlated with both HRM $(r=0 \cdot 70 ; 95 \%$ CI $0 \cdot 62$, $0 \cdot 76)$ and $24 \mathrm{~h}-\mathrm{R}(r=0 \cdot 81 ; 95 \%$ CI $0 \cdot 77,0 \cdot 84)$. It featured acceptable agreement with both criterion measures, slightly underestimating TEE compared with $24 \mathrm{~h}-\mathrm{R}$ $(-2 \cdot 8 \%$, mean of individual differences $-272 \cdot 7 \mathrm{~kJ} / \mathrm{d} ; 95 \% \mathrm{CI}-490 \cdot 6,-57 \cdot 4 \mathrm{~kJ} / \mathrm{d})$ and moderately overestimating it compared with $\mathrm{HRM}(+11 \cdot 3 \%$, mean of individual differences $+1106 \cdot 2 \mathrm{~kJ} / \mathrm{d}$; $95 \%$ CI $845 \cdot 8,1366 \cdot 6 \mathrm{~kJ} / \mathrm{d}$ ). Reliability ranged from moderate to good (weighted kappa coefficients from $0 \cdot 47$ to $0 \cdot 78$ and intra-class correlation coefficients between 0.79 and 0.86 for energy expenditure by PA categories), indicating strong agreement between the two assessments.

Conclusions: This PAFQ could be useful in the description and surveillance of PA patterns or for the evaluation of population-based interventions directed at promoting PA in Tunisian children and adolescents.
\end{abstract}

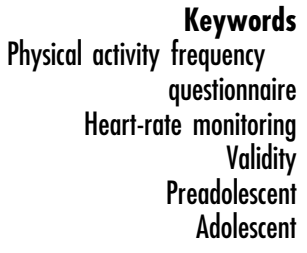

Over the past two decades evidence has shown that childhood overweight and obesity and their co-morbidities are increasing worldwide ${ }^{(1-6)}$. Like many other South and East Mediterranean countries, Tunisia is experiencing an advanced nutrition transition followed by the increase of overweight and obesity prevalence in adolescent boys and girls aged 15-19 years that has reached $17 \cdot 4$ and $20 \cdot 7 \%$, respectively ${ }^{(7,8)}$. Insufficient physical activity (PA) has been identified as the fourth leading risk factor for death and disability associated with obesity and its co-morbidities ${ }^{(9)}$. Moreover, regular PA early in life is associated with major health benefits, including decreased adiposity, lower blood lipids, lower blood pressure and greater bone mineral density $^{(10-12)}$, and could prevent or delay the onset of chronic diseases later in life ${ }^{(13,14)}$. There is dearth of information related to lifestyle factors especially PA in Tunisia ${ }^{(15)}$.

Thus, prevention wise, the understanding of the different dimensions and patterns of PA among youth in this context states the need for accurate assessment instruments. A variety of PA measurement methods do exist such as PA questionnaires (PAQ), direct observation, mechanical or electronic monitoring, or doubly labelled water $^{(16)}$. Each method has its own utilities and limits in terms of accuracy, cost, versatility and practicality in free-living situations for the evaluation of average daily energy expenditure (EE) and dose-response associations with health outcomes based on recommended PA or EE 
cut-off points ${ }^{(17,18)}$. Although simplified and relatively cheap versions of the heart-rate monitoring (HRM) technique have been devised to be used in epidemiological investigations $^{(19,20)}$, a specific usefulness of the PAQ method is that it also provides detailed quantitative and qualitative assessment of the entire spectrum of activity and inactivity ${ }^{(21-26)}$ allowing a variety of analysis purposes, e.g. habitual PA patterns ${ }^{(27)}$.

Several questionnaires have been developed for children and adolescents, such as that of the Behavioral Risk Factor Surveillance System (BRFSS) ${ }^{(28)}$, the International Physical Activity Questionnaire (IPAQ) ${ }^{(29)}$ or the Arab Teens Lifestyle Study (ATLS) PA questionnaire ${ }^{(30)}$, and can be used for specific purposes such as ranking, grouping or categorizing PA levels, and possibly assessing some aspects of low, moderate and vigorous $\mathrm{PA}^{(31)}$. However, it would seem that more comprehensive self-report questionnaires aiming at assessing all forms of activity performed during the day are essential. These questionnaires are specifically important for the assessment of the pattern and mode of PA in preadolescent and adolescent Tunisians in different cultural settings. Also, previous research has indicated that the reliability and validity of PAQ varies according to ethnicity ${ }^{(32)}$.

The objectives of the present study were thus to develop and validate a Physical Activity Frequency Questionnaire (PAFQ) specific to Tunisian adolescents.

\section{Methods}

\section{Participants}

The validation sample size was based on the recommendation that 100-200 subjects should be interviewed ${ }^{(33)}$. Participants were 150 volunteers from two elementary schools and two high schools in the Greater Tunis region (the most economically developed and urbanized area including the capital city). Data were collected between March and June 2008, a period when the climate allows a mix of indoor and outdoor activities which cover the whole range of $\mathrm{EE}$.

\section{Etbical approval}

The study was conducted according to the guidelines laid down in the Declaration of Helsinki. The protocol was approved by the Ethic Committee on Human Research of the National Institute of Nutrition. After the participants' parents had been thoroughly informed about the purpose, requirements and procedures, all participants gave free informed verbal consent which was witnessed and formally recorded.

\section{Antbropometry}

Anthropometric measurements were taken at the beginning of the study following standard procedures ${ }^{(34)}$; all volunteers wore light clothing but no shoes or socks.
Height was measured to the nearest $0 \cdot 1 \mathrm{~cm}$ with a wall-mounted stadiometer (Person-check ${ }^{\circledR}$; Kirchner \& Wilhelm, Germany). Weight was measured to the nearest $0 \cdot 1 \mathrm{~kg}$ on a calibrated scale (Detecto, USA).

\section{Development of the physical activity frequency questionnaire}

The PAFQ was designed and developed in several steps. As insufficient data were available concerning the PA profile of adolescents in Tunisia, a new inventory was made using a series of $24 \mathrm{~h}$ PA recalls $(24 \mathrm{~h}-\mathrm{R})^{(35)}$ carried out on a sample of forty volunteer Tunisian adolescents (10-19 years old), diversified by area (urban/rural) and gender to cover a range of different situations. Each participant answered the $24 \mathrm{~h}-\mathrm{R}$ three times, i.e. on Sunday (rest day), Monday (full day of school) and Saturday (half day of school). Each day was divided into 5-min blocks and the respondent was prompted to report the type of the activity performed during each block as the day progressed using time cues. Information was also collected about specific characteristics of each activity while it was being performed, e.g. the body position (sitting, standing, lying down or in locomotion) and intensity (carrying a load, or not).

The energy cost of each activity was calculated by multiplying the time spent by the corresponding metabolic equivalent of task (MET) value, taken from the compendium of physical activities for youth ${ }^{(36)}$ modelled on the previous adult compendium of physical activities ${ }^{(37)}$. For each participant, the total daily energy expenditure (TEE) was estimated as the sum of all EE over the three $24 \mathrm{~h}$ periods divided by three, and the mean overall TEE was defined as the average of TEE over the forty participants. The relative contribution of each activity to TEE was computed, and activities that contributed up to $95 \%$ of mean overall TEE were included in the questionnaire. Activities that were not significant with respect to the whole sample but that contributed $\geq 10 \%$ to one individual's TEE were also included ${ }^{(38)}$.

The final list consisted of fifty-four different physical activities classified in eight sections: (i) at home (personal care, nursing, household chores, cooking); (ii) meals; (iii) school time; (iv) transport; (v) non-sport leisure activities; (vi) sports; (vii) prayer; and (viii) sleeping. A $7 \mathrm{~d}$ interview questionnaire, which took both school and rest days into account, was then designed in Arabic for use among the adolescents. For each activity, the frequency and length of time spent were detailed. Weekly frequency was scored from 0 (never) to 7 (every day). Possible durations ranged from 0 to $8 \mathrm{~h} / \mathrm{d}$ with a precision of $15 \mathrm{~min}$. A pilot test was conducted among ten adolescents (10-19 years old) to assess whether the PAFQ was easy for them to read and understand. Minor changes were made including the use of age-appropriate language and a more appealing layout for young people. The final version of the questionnaire was designed to be 
interviewer-administered and answering all the questions took about $30 \mathrm{~min}$ (see online supplementary material for a version translated from French/Arabic to English).

After data collection and acquisition, for each activity, frequency and duration were converted into minutes per day. If the amount of time declared was less than $24 \times 60=1440 \mathrm{~min} / \mathrm{d}$, TEE was completed by the resting energy expenditure estimated with the Schofield-HW equations ${ }^{(39)}$ using sex, height and weight, as they are recommended for mixed populations of obese and non-obese children and adolescents ${ }^{(40)}$; if it was more than $1440 \mathrm{~min} / \mathrm{d}$, the energy cost of each activity was proportionately adjusted so that the corrected time spent added up to one day. Then EE for each activity was then derived using the compendium of physical activities as described above.

For data analysis and presentation purposes, the fiftyfour activities from the eight categories were arranged in twenty-five groups and twenty-four groups (with the exclusion of sleep) were classified according to MET values into low- $($ MET < 3), moderate- $($ MET 3-6) and high-intensity activities $(\text { MET } \geq 6)^{(41,42)}$.

\section{Validation study}

To validate the PAFQ, PA estimations based on the questionnaire were compared with those derived from both an objective instrument, HRM, and a subjective one, 24h-R, on the same individuals.

\section{Heart-rate monitoring}

The HRM technique is based on the linear relationship between heart rate (HR) and oxygen consumption ${ }^{(43,44)}$ and has been shown to be a valid indicator of $\mathrm{EE}$ and activity levels in youth ${ }^{(31)}$. HR was recorded in free-living conditions over a continuous $3 \mathrm{~d}$ period (including one weekday and two weekend days) by an electrode-belt worn around the chest that detected and stored the mean HR at 5-min intervals (S610i; Polar Instruments, Kempele, Finland). Data were downloaded to a computer for storage using a Polar propriety interface and software. All non-physiological values ( $>215$ or $<45$ beats/min) were replaced by the average of the adjacent value, and individual files were discarded if the total aberrant values exceeded $3 \%$ of the file ${ }^{(45)}$. Before wearing a HR monitor, each participant's maximum oxygen uptake and maximum heart rate $\left(\mathrm{HR}_{\max }\right)$ were assessed using the Léger test $^{(46)}$. The value used as the resting heart rate $\left(\mathrm{HR}_{\text {rest }}\right)$ was the average HR during sleep, and the heart rate reserve (HRR) was calculated as the difference between $\mathrm{HR}_{\max }$ and $\mathrm{HR}_{\text {rest. The Karvonen formula }}{ }^{(47)}$ was then used to calculate the daily physical activity intensity (PAI) expressed as a percentage of HRR and based on both maximum and resting heart: PAI $(\%)=\left[\left(\mathrm{HR}_{\text {daily }}-\mathrm{HR}_{\text {rest }}\right) /\right.$ $\mathrm{HRR}] \times 100$. To estimate TEE, we assumed the percentage of HRR and $\mathrm{VO}_{2}$ reserve were equivalent, and used the energy equivalent to convert the rate of oxygen consumption into an EE rate ${ }^{(48)}$. Since the EE estimate derived from the PAFQ did not include the thermic effect of food (TEF), it was assumed that $10 \%$ of the TEE was due to TEF and this was subtracted from the TEE assessed by HRM. Moreover, contrary to what happens in younger children, in the age group under study energy for growth is weak (i.e. between 0 and $1.5 \%$ of TEE) ${ }^{(49)}$, and it was decided not to take this into account. The different activity intensities were classified based on percentage usage of the individual's personal HRR: low ( $<40 \%$ HRR), moderate (40-70\% HRR) and high intensity $(>70 \% \mathrm{HRR})^{(47)}$.

\section{$24 \mathrm{~h}$ Physical activity recall}

A $24 \mathrm{~h}-\mathrm{R}$ protocol ${ }^{(50)}$ was used simultaneously to validate the PAFQ. The adolescents were asked to note down their activities while wearing the HR monitor. The $24 \mathrm{~h}-\mathrm{R}$ was prompted by trained interviewers asking about segments of the day starting when the HR monitor was first worn and ending with its retrieval. The adolescents were encouraged to account for the entire time they wore the monitor.

\section{Reliability study}

The reliability of the PAFQ was evaluated using a testretest design $^{(31)}$. The PAFQ was interviewer-administered once on the day following the end of the HRM sequence and once one month later.

\section{Data processing and analysis}

Data entry screens including quality checks as well as validation by double entry used Epi-Data software version 3.1. Data management and analysis were performed using the statistical software packages Stata version 11 and SPSS $15 \cdot 0$ for Windows. Results are presented as estimates and their standard deviations or $95 \%$ confidence intervals.

\section{Validation}

We assessed relationships between the PAFQ and HRM or 24h-R by scatter diagrams and computing Pearson's correlation coefficients. Agreement between the PAFQ and HRM or $24 \mathrm{~h}-\mathrm{R}$ was assessed using a plot of the differences between the two methods $v$. the average of the measurements according to the Bland-Altman technique ${ }^{(51)}$; the magnitude and direction of the bias of the PAFQ was assessed as the mean of individual differences and precision as the standard deviation of those differences. In addition, Spearman correlation coefficients were used to examine the associations between self-reported time spent in various activity intensities and data from both HRM and $24 \mathrm{~h}-\mathrm{R}$.

\section{Reliability}

Agreement between the two replicates of PAFQ from the test-retest procedures was assessed by within-subject intra-class correlation coefficients (ICC) derived using 
one-factor ANOVA and using weighted kappa $\left(\boldsymbol{\kappa}_{\mathrm{w}}\right)$ statistics (for interpretation, $\kappa_{\mathrm{w}} \leq 0.09$ indicated poor agreement, $\boldsymbol{\kappa}_{\mathrm{w}}=0 \cdot 10-0 \cdot 20$ slight agreement, $\boldsymbol{\kappa}_{\mathrm{w}}=0 \cdot 21-0 \cdot 40$ fair agreement, $\kappa_{\mathrm{w}}=0 \cdot 41-0.60$ moderate agreement, $\kappa_{\mathrm{w}}=$ $0 \cdot 61-0 \cdot 80$ substantial agreement, and $\boldsymbol{\kappa}_{\mathrm{w}}=0 \cdot 81-1 \cdot 00$ indicated almost perfect agreement $\left.{ }^{(52)}\right)$. The test-retest reliability was assessed for TEE and also for EE in each of the eight categories of PA in the questionnaire.

\section{Results}

\section{Participants}

Among the 150 originally recruited participants, eight did not complete all the stages of the study, so that the validation was finally based on a sample of 142 volunteers (seventy-one girls, seventy-one boys) aged 10-19 years (mean 14.5 (sD 3.0) years); most of them were urban (93\%), 43\% attended elementary school and 57\% secondary school.

(a)

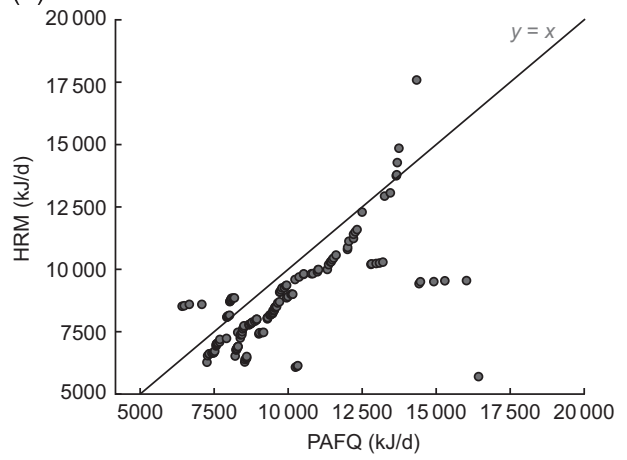

\section{Validation}

Scatter diagrams (Fig. 1) and correlation coefficients indicated a strong linear relationship between the participants' TEE estimated by the PAFQ and both HRM $(r=0 \cdot 70 ; 95 \%$ CI $0 \cdot 62,0 \cdot 76)$ and $24 \mathrm{~h}-\mathrm{R}(r=0 \cdot 81 ; 95 \% \mathrm{CI}$ $0 \cdot 77,0 \cdot 84)$, despite some outliers. The paired data points were somewhat away from the diagonal line, indicating a not perfect individual agreement between TEE assessed with the PAFQ and 24h-R, or especially HRM. Indeed, mean overall TEE (Table 1 ) estimated by the questionnaire tended to be higher $(+11 \cdot 3 \%)$ than by HRM, but lower $(-2 \cdot 8 \%)$ than by $24 \mathrm{~h}-\mathrm{R}$. Also, the Bland-Altman plot (Fig. 2(a)), which assessed the agreement between participants' TEE estimated by PAFQ $v$. HRM, showed some amount of bias: the mean of individual PAFQ - HRM differences was $+1106 \cdot 2 \mathrm{~kJ} / \mathrm{d}(95 \%$ CI $845 \cdot 8,1366 \cdot 6 \mathrm{~kJ} / \mathrm{d})$. On the other hand, the bias for TEE estimated by PAFQ $v$. $24 \mathrm{~h}-\mathrm{R}$ as represented in the corresponding Bland-Altman plot (Fig. 2(b)) was reversed and of smaller absolute value: mean of individual PAFQ - 24h-R differences was

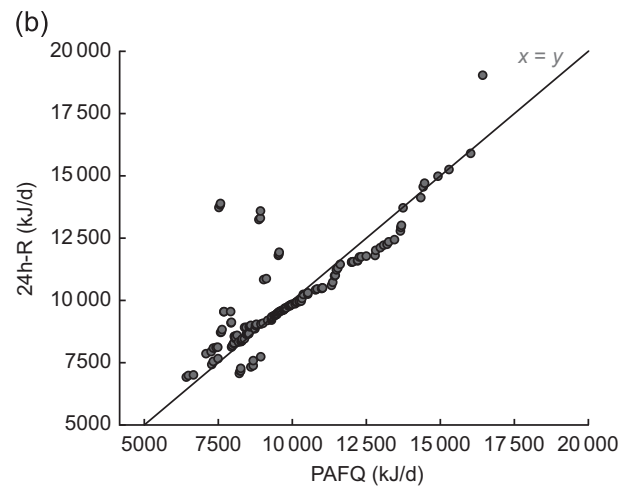

Fig. 1 Validation of the Physical Activity Frequency Questionnaire (PAFQ): scatter diagrams of daily total energy expenditure estimated by the PAFQ $v$. (a) heart-rate monitoring (HRM) or (b) $24 \mathrm{~h}$ physical activity recall (24h-R) among Tunisian preadolescent and adolescent children aged 10-19 years ( $n$ 142), March-June 2008. Solid line represents perfect agreement (line of equality, $y=x)$. Pearson correlation coefficient, $r(95 \% \mathrm{Cl}): 0.70(0 \cdot 62,0 \cdot 76)$ for PAFQ $v$. HRM; $0 \cdot 81(0 \cdot 77,0.84)$ for PAFQ v. 24h-R

Table 1 Daily total energy expenditure (TEE) estimated by the Physical Activity Frequency Questionnaire (PAFQ), heart-rate monitoring (HRM) and $24 \mathrm{~h}$ physical activity recall $(24 \mathrm{~h}-\mathrm{R})$ methods, and Spearman correlations between the time spent in different activity levels estimated by the PAFQ and each reference method, among Tunisian preadolescent and adolescent children aged 10-19 years ( $n$ 142), March-June 2008

\begin{tabular}{lcccccr}
\hline & & \multicolumn{3}{c}{ TEE $(\mathrm{kJ} / \mathrm{d})$} \\
\cline { 3 - 7 } Instrument & $n$ & Mean & SD & Minimum & Median & Maximun \\
\hline PAFQ & 142 & $9797 \cdot 1$ & $2112 \cdot 9$ & $6418 \cdot 5$ & $9803 \cdot 8$ & $16430 \cdot 4$ \\
HRM & 142 & $8691 \cdot 7$ & $1907 \cdot 6$ & $5700 \cdot 3$ & $8366 \cdot 9$ & $17588 \cdot 9$ \\
24h-R & 142 & $10069 \cdot 6$ & $2093 \cdot 8$ & $6921 \cdot 9$ & $9571 \cdot 9$ & $19040 \cdot 6$
\end{tabular}

Spearman correlation coefficients of the time spent $(\mathrm{min} / \mathrm{d})$

\begin{tabular}{|c|c|c|c|c|c|c|}
\hline & \multicolumn{2}{|c|}{ Low activity } & \multicolumn{2}{|c|}{ Moderate activity } & \multicolumn{2}{|c|}{ High activity } \\
\hline & $r$ & $95 \% \mathrm{Cl}$ & $r$ & $95 \% \mathrm{Cl}$ & $r$ & $95 \% \mathrm{Cl}$ \\
\hline $\begin{array}{l}\text { PAFQ v. HRM } \\
\text { PAFQ v. } 24 \mathrm{~h}-\mathrm{R}\end{array}$ & $\begin{array}{l}0.29 \\
0.67\end{array}$ & $\begin{array}{l}0.21,0.37 \\
0.52,0.71\end{array}$ & $\begin{array}{l}0.55 \\
0.63\end{array}$ & $\begin{array}{l}0.41,0.64 \\
0.49 \\
0.70\end{array}$ & $\begin{array}{l}0.72 \\
0.75\end{array}$ & $\begin{array}{l}0.61,0.78 \\
0.63,0.79\end{array}$ \\
\hline
\end{tabular}


(a)

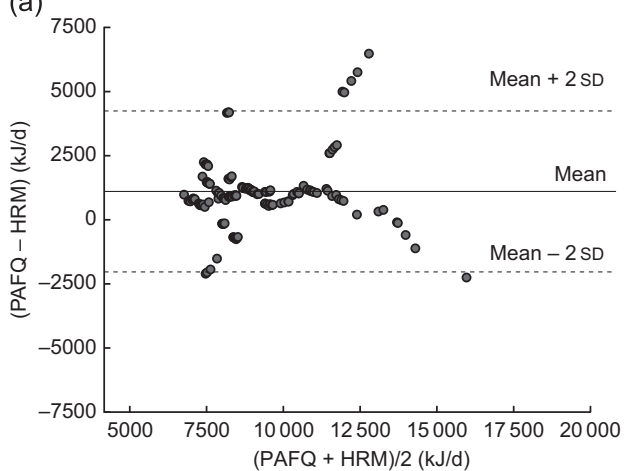

(b)

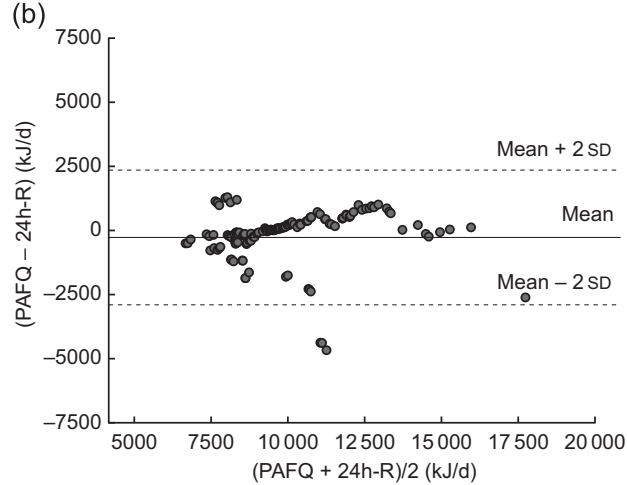

Fig. 2 Validation of the Physical Activity Frequency Questionnaire (PAFQ): Bland-Altman plots of the differences in daily total energy expenditure estimated by the PAFQ and (a) heart-rate monitoring (HRM) or (b) the $24 \mathrm{~h}$ physical activity recall (24h-R) $v$. the average of the two methods among Tunisian preadolescent and adolescent children aged 10-19 years ( $n$ 142), March-June 2008. The horizontal solid line represents the mean of the differences (bias) and the dashed lines the mean of the differences $\pm 2 \mathrm{SD}$ of the differences (lower and upper limits of agreement)

Table 2 Test-retest reliability of the Physical Activity Frequency Questionnaire (PAFQ): weighted kappa coefficients $\left(\kappa_{\mathrm{w}}\right)$ and within-subject intra-class correlation coefficients (ICC) of estimated energy expenditure according to the eight physical activity categories among Tunisian preadolescent and adolescent children aged 10-19 years (n 142), March-June 2008

\begin{tabular}{|c|c|c|c|c|}
\hline \multirow[b]{2}{*}{ Physical activity category ( $n$ 8) } & \multicolumn{2}{|c|}{$\kappa_{\mathrm{w}}$} & \multicolumn{2}{|c|}{ ICC } \\
\hline & Estimate & $95 \% \mathrm{Cl}$ & Estimate & $95 \% \mathrm{Cl}$ \\
\hline At home (e.g. personal care, nursing, household chores, cooking) & $0 \cdot 47$ & $0.23,0.77$ & $0 \cdot 79$ & $0.53,0.89$ \\
\hline Meals (at home and/or outside the home) & 0.51 & $0.33,0.78$ & $0 \cdot 83$ & $0 \cdot 66,0 \cdot 88$ \\
\hline School work (time, physical position) & 0.64 & $0.42,0.81$ & $0 \cdot 88$ & $0.79,0.91$ \\
\hline Transport (going to school or not) & $0 \cdot 71$ & $0.53,0.82$ & $0 \cdot 89$ & $0.68,0.92$ \\
\hline Non-sport leisure activities (during and out of school days) & 0.53 & $0.22,0.68$ & $0 \cdot 86$ & $0.71,0.94$ \\
\hline Sports & 0.62 & $0.26,0.79$ & $0 \cdot 82$ & $0.72,0.93$ \\
\hline Prayers (with physical position change) & $0 \cdot 78$ & $0 \cdot 38,0 \cdot 81$ & 0.93 & $0.86,0.95$ \\
\hline Sleeping (at week days and weekend) & 0.65 & $0 \cdot 56,0 \cdot 84$ & 0.91 & $0.79,0.94$ \\
\hline Daily total energy expenditure & $0 \cdot 61$ & $0.50,0.71$ & $0 \cdot 86$ & $0.71,0.99$ \\
\hline
\end{tabular}

$-272 \cdot 7 \mathrm{~kJ} / \mathrm{d}(95 \% \mathrm{CI}-490 \cdot 6,-57 \cdot 4 \mathrm{~kJ} / \mathrm{d})$. On both plots, there was no obvious pattern of differences which were scattered around the bias; precision (as assessed by upper and lower limits of agreement on the Bland-Altman plots) of estimation of TEE by PAFQ was better for $24 \mathrm{~h}-\mathrm{R}$ $(-2900 \cdot 2$ and $+2353 \cdot 0 \mathrm{~kJ} / \mathrm{d})$ than for HRM $(-2033 \cdot 1$ and $+4245 \cdot 4 \mathrm{~kJ} / \mathrm{d})$. The Spearman correlation coefficients between the individuals' time spent in low-, moderateand high-intensity activities estimated by PAFQ and HRM were significant and moderate $(r=0.55-0.72)$ except during light activity $(r=0 \cdot 29)$, while the PAFQ and the 24h-R showed significant and moderate correlations $(r=0 \cdot 67-0 \cdot 75)$ across all ranges of intensity (Table 1$)$.

\section{Reliability}

Overall mean TEE over the 142 participants for the two administrations of the PAFQ was 9797.1 (sD 2112.9) $\mathrm{kJ} / \mathrm{d}$ and $9538.1(\mathrm{sD} 1890 \cdot 9) \mathrm{kJ} / \mathrm{d}$; the mean of individual differences was $259 \cdot 0 \mathrm{~kJ} / \mathrm{d}(95 \%$ CI $121 \cdot 3,396 \cdot 8 \mathrm{~kJ} / \mathrm{d})$, showing no systematic departure from the null hypothesis (paired $t$ test $P=0 \cdot 152$ ). Within-subject ICC for the two replicates of the PAFQ was $0 \cdot 86$ (95\% CI $0 \cdot 71,0 \cdot 99)$ for TEE and ranged between 0.79 and 0.93 for EE by PA category. The $\kappa_{\mathrm{w}}$ value for TEE over test-retest was $0 \cdot 61$ $(95 \%$ CI $0.50,0 \cdot 71)$ and $\kappa_{\mathrm{w}}$ coefficients by category of PA ranged from $0 \cdot 47$ to $0 \cdot 78$ (Table 2 ).

\section{Energy expenditure by activities assessed by the physical activity frequency questionnaire}

Participants showed low daily EE in high-intensity $(16.8 \mathrm{~min} / \mathrm{d}$, i.e. $1.9 \%$ of waking time) and moderate-intensity $(101 \cdot 1 \mathrm{~min} / \mathrm{d}$, i.e. $11 \cdot 5 \%$ of waking time) PA like sports, home activities or walking (Table 3); the EE spent sitting, standing, studying, using television/computer, playing board games, eating and using motorized transport $(760 \cdot 2 \mathrm{~min} / \mathrm{d}$, i.e. $86 \cdot 6 \%$ of waking time) was higher. The contribution to the estimated daily TEE was $21 \%$ for sleeping, $6 \%$ for high-, $15 \%$ for moderate- and 58\% for low-intensity activities.

\section{Discussion}

In a context of increasing prevalence of overweight and obesity, understanding PA behaviours is of major importance prevention wise. We developed a PAFQ, which lists fifty-four different activities and then classified into 
Table 3 Time spent and energy expenditure estimated by the Physical Activity Frequency Questionnaire for the twenty-five groups of activities among Tunisian preadolescent and adolescent children aged 10-19 years ( $n$ 142), March-June 2008

\begin{tabular}{|c|c|c|c|c|c|c|c|}
\hline \multirow[b]{2}{*}{ Physical activity group ( $n 25$ ) } & \multirow{2}{*}{$\begin{array}{c}\begin{array}{c}\text { Participants reporting } \\
\text { the activity }\end{array} \\
\%\end{array}$} & \multicolumn{2}{|c|}{$\begin{array}{l}\text { Duration } \\
\text { (min/d) }\end{array}$} & \multicolumn{2}{|c|}{$\begin{array}{l}\text { Energy expenditure } \\
(\mathrm{MET} \times \mathrm{min} / \mathrm{d})\end{array}$} & \multicolumn{2}{|c|}{$\begin{array}{c}\text { Energy } \\
\text { expenditure (kJ/d) }\end{array}$} \\
\hline & & Mean & SD & Mean & SD & Mean & SD \\
\hline Sleep & 100 & $562 \cdot 0$ & $56 \cdot 9$ & $505 \cdot 8$ & $21 \cdot 8$ & $2044 \cdot 8$ & $129 \cdot 4$ \\
\hline \multicolumn{8}{|l|}{ Low-intensity activities $(<3 \mathrm{MET})^{\star}$} \\
\hline School work: listening, taking notes, studying, sitting, standing & 100 & 333.9 & $30 \cdot 8$ & $479 \cdot 6$ & $32 \cdot 2$ & $1954 \cdot 4$ & $235 \cdot 3$ \\
\hline Leisure: watching television, using computer, playing board games & 100 & $99 \cdot 2$ & $17 \cdot 9$ & $131 \cdot 0$ & $29 \cdot 6$ & $553 \cdot 1$ & $103 \cdot 0$ \\
\hline Family reunion activities & 86 & $72 \cdot \overline{9}$ & $24 \cdot 5$ & $109 \cdot 4$ & $26 \cdot 8$ & $453 \cdot 4$ & $58 \cdot 2$ \\
\hline Leisure: reading, listening to music/radio, drawing, sitting & 46 & $77 \cdot 9$ & $20 \cdot 9$ & $106 \cdot 6$ & $12 \cdot 8$ & $426 \cdot 2$ & $45 \cdot 6$ \\
\hline Self care & 100 & $50 \cdot 7$ & $14 \cdot 3$ & $101 \cdot 4$ & $28 \cdot 6$ & $409 \cdot 1$ & $59 \cdot 0$ \\
\hline Eating: sitting/standing & 100 & $83 \cdot 8$ & $17 \cdot 9$ & $86 \cdot 9$ & $14 \cdot 3$ & $350 \cdot 9$ & $62 \cdot 4$ \\
\hline Shopping & 99 & $22 \cdot 4$ & $8 \cdot 6$ & $51 \cdot 5$ & $21 \cdot 2$ & $208 \cdot 9$ & $100 \cdot 1$ \\
\hline Transport: riding in a car/bus/train - sitting/standing & 52 & $14 \cdot 0$ & $9 \cdot 3$ & $20 \cdot 3$ & $8 \cdot 3$ & $85 \cdot 0$ & $37 \cdot 3$ \\
\hline Home activities: light effort & 70 & $10 \cdot 2$ & 4.5 & $19 \cdot 4$ & $9 \cdot 8$ & $77 \cdot 5$ & $23 \cdot 4$ \\
\hline Praying & 26 & $7 \cdot 8$ & $4 \cdot 3$ & $10 \cdot 9$ & 3.5 & $44 \cdot 0$ & $11 \cdot 3$ \\
\hline Packing/unpacking bag & 92 & $4 \cdot 2$ & $1 \cdot 1$ & $10 \cdot 5$ & $3 \cdot 3$ & $42 \cdot 3$ & $5 \cdot 9$ \\
\hline Child care & 16 & $3 \cdot 8$ & $2 \cdot 5$ & $9 \cdot 6$ & $5 \cdot 5$ & $39 \cdot 4$ & $19 \cdot 7$ \\
\hline Cooking & 30 & $4 \cdot 1$ & $1 \cdot 3$ & $8 \cdot 3$ & $3 \cdot 2$ & $33 \cdot 9$ & $24 \cdot 7$ \\
\hline Taking a nap & 13 & $3 \cdot 3$ & $2 \cdot 1$ & $3 \cdot 0$ & $2 \cdot 6$ & $12 \cdot 1$ & $9 \cdot 2$ \\
\hline Total low-intensity activities & 100 & $760 \cdot 2$ & $98 \cdot 1$ & $1412 \cdot 2$ & $104 \cdot 4$ & $5684 \cdot 4$ & $770 \cdot 0$ \\
\hline \multicolumn{8}{|l|}{ Moderate-intensity activities ( 3 to $<6 \mathrm{MET})^{*}$} \\
\hline Walking & 100 & $38 \cdot 9$ & $14 \cdot 7$ & $140 \cdot 2$ & $27 \cdot 1$ & $575 \cdot 3$ & 113.9 \\
\hline Running & 35 & $30 \cdot 7$ & $13 \cdot 2$ & $129 \cdot 1$ & $20 \cdot 6$ & 504.9 & $137 \cdot 3$ \\
\hline Sports: moderate effort & 82 & $11 \cdot 1$ & $4 \cdot 7$ & $51 \cdot 2$ & $14 \cdot 5$ & $210 \cdot 2$ & $72 \cdot 0$ \\
\hline Home activities: vigorous effort & 29 & $11 \cdot 9$ & $5 \cdot 5$ & $42 \cdot 6$ & $9 \cdot 8$ & $178 \cdot 4$ & $42 \cdot 7$ \\
\hline Leisure: dancing, unstructured indoor play & 38 & $6 \cdot 5$ & 3.9 & $29 \cdot 7$ & $11 \cdot 6$ & $108 \cdot 4$ & $36 \cdot 0$ \\
\hline Home repair & 20 & 1.9 & 1.5 & $4 \cdot 8$ & $3 \cdot 8$ & $20 \cdot 1$ & $10 \cdot 9$ \\
\hline Total moderate-intensity activities & 100 & $101 \cdot 0$ & $28 \cdot 2$ & 397 & $50 \cdot 3$ & $1596 \cdot 8$ & $455 \cdot 5$ \\
\hline \multicolumn{8}{|l|}{ High-intensity activities $(\geq 6 \mathrm{MET})^{*}$} \\
\hline Sports: hard effort & 18 & $8 \cdot 4$ & $5 \cdot 3$ & $55 \cdot 5$ & $13 \cdot 7$ & $226 \cdot 1$ & $59 \cdot 0$ \\
\hline Bicycling & 16 & $3 \cdot 3$ & $1 \cdot 2$ & $20 \cdot 0$ & $11 \cdot 3$ & $80 \cdot 4$ & $36 \cdot 0$ \\
\hline Climbing stairs moderate effort & 91 & $2 \cdot 4$ & $1 \cdot 7$ & $17 \cdot 1$ & $8 \cdot 2$ & $72 \cdot 0$ & $42 \cdot 3$ \\
\hline Walking uphill & 29 & $2 \cdot 6$ & 1.9 & 16.0 & $5 \cdot 2$ & $73 \cdot 7$ & $33 \cdot 1$ \\
\hline Total high-intensity activities & 94 & $1 \overline{6} \cdot 8$ & 8.5 & $119 \cdot 0$ & $48 \cdot \overline{6}$ & $477 \cdot 7$ & $183 \cdot 0$ \\
\hline
\end{tabular}


twenty-five groups and eight categories, to document in depth the various dimensions and patterns of PA in free-living Tunisian preadolescents and adolescents. We estimated its validity both $v$. one objective instrument (HRM with individual calibration) and one subjective instrument (a $24 \mathrm{~h}-\mathrm{R}$ of daily activities) and we assessed its reliability by a test-retest procedure at a 1-month interval.

\section{Development of the physical activity frequency questionnaire}

Development of the questionnaire including a pilot study and use of age-appropriate language resulted in a final version of the questionnaire which was understandable among the target population of preadolescents and adolescents. Nevertheless, given the complexity, especially for young adolescents, to estimate with precision the duration and intensity of their activities ${ }^{(53)}$, and particularly in the Tunisian context, the PAFQ was designed as an interviewer-administered rather than a self-report questionnaire. Answering all the questions took about 30 min which seemed acceptable for the participants and compatible with use of the PAFQ in large-scale studies.

\section{Validity}

As for the validity, the PAFQ was strongly correlated with both HRM and 24h-R and featured acceptable agreement with both criterion measures, with a better result $v$. 24h-R than $v$. HRM. Indeed, validity analysis using Bland-Altman plots revealed an acceptable moderate amount of bias (although larger for HRM than 24h-R), despite the fact that a few outlying data points were included in the analysis while their exclusion would have improved our results (detailed data not shown). The HRM method is well recognized as not being a good predictor of $\mathrm{EE}$ at low compared with higher levels of $\mathrm{PA}^{(54)}$ and this could explain the lower validity of the PAFQ $v$. the HRM method in low-activity individuals. Because of methodological issues (including inappropriate use of correlation coefficients for quantification of validity in many studies ${ }^{(51)}$ ) it is not always possible to make direct comparisons with the findings of other studies, but the characteristics of the PAFQ $v$. HRM or $24 \mathrm{~h}-\mathrm{R}$ appeared to be comparable with other instruments. For example, in a sample of forty-four middle- and high-school students in South Carolina, Weston et al. ${ }^{(55)}$ reported correlation coefficients of $0 \cdot 88$, 0.77 and 0.53 between relative EE from a previous day recall of $\mathrm{PA}$ and a pedometer, Caltrac counts and percentage HR range, respectively. In addition, several validation studies, reviewed by Kohl et al. ${ }^{(31)}$, which examined among children and adolescents self- or interviewer-administered recall of PA using HRM as criterion measure, revealed correlation coefficients ranging from $0 \cdot 25$ to $0 \cdot 58$.

\section{Reliability}

Regarding reliability during the test-retest procedure the ICC was 0.86 and not less than 0.79 for EE by PA categories, indicating strong agreement between the two assessments; also values of $\boldsymbol{\kappa}_{\mathrm{w}}$ indicated moderate to substantial test-retest reliability according to the components of the estimated TEE. Variability of PA habits or technical errors may negatively affect reliability although it is not possible to distinguish between both. The quite satisfactory level of reliability could have been due to both the comprehensiveness of various types of PA in the questionnaire and the good understanding of questions due to careful testing at the development stage. Furthermore, test-retest reliability is known to improve with time when self-report techniques are used ${ }^{(38,56,57)}$. Also as the PAFQ was an interviewer-administered questionnaire, a trained interviewer may also have an important role in the strength of the reliability results.

\section{Metbodological strengtbs and limitations of the study}

A validation sample composed of volunteers who were mostly urban and attending schools from around the capital city could be a limit of the present study, especially regarding large-scale use of the PAFQ. But levels of TEE among the surveyed participants indeed showed a wide range of values and the mean overall level of PA was coherent with results observed in the same context on a much larger sample (although with a questionnaire adapted from one developed for adults) ${ }^{(8)}$. Also in the context of socio-economic changes and socio-cultural evolution there seems to be a trend towards convergence of lifestyles (including PA behaviours with more time spent on sedentary activities) whatever the area of residence $^{(58)}$. Although the questionnaire was developed in Tunisia, it likely has broader applicability to other North African countries; indeed, these countries share with Tunisia both a number of socio-cultural features linked to the Arab-Muslim culture and the common consequences on lifestyle factors such as diet and PA of socio-economic and societal changes due to globalization and modernization.

There are a number of advantages in using the present PAFQ in comparison with many other PAQ designs related to both its detailed content and the proposed mode of administration. First, its interviewer-administered format ensured the quality of the data collected. Second, PAFQ produces a high level of detail for PA behaviours across different domains of free-living teenagers, which may be useful in identifying common activities that could be appropriate targets for behavioural interventions to improve PA at a large scale. Third, the assignment of different intensity categories and body postures for each activity can reduce the magnitude of errors in intensity level reported. Fourth, a distinction between school and rest days over the habitual week such as developed in our PAFQ on one hand, and the closed questions and specific time slots on the other hand, may be able to minimize duration reporting errors. Indeed, reducing errors of the 
two basic elements of dose (intensity and time spent) may be an important approach to reduce overall measurement errors in self-report data ${ }^{(59)}$.

Validation of the PAFQ $v$. both a subjective instrument (the 24h-R) and an objective one (the HRM method) was also a strength of the study. Nevertheless, a limitation of assessing PA based on HR data is the confounding effect of factors other than energy demand on the HR response to exercise; for example, high ambient temperature, time of day, emotional state, dehydration, food and caffeine intake, smoking, body position, muscle groups used and illness ${ }^{(54,60,61)}$. However, when applied to groups of individuals, the HRM technique provides an acceptable estimate of TEE and associated patterns of $\mathrm{PA}^{(44)}$. Objective measures of PA fitness with multiple motion sensors or HRM have often been used as a criterion measure in field studies validating other subjective PA instruments, particularly selfreport instruments ${ }^{(16)}$. Some recent questionnaire validation studies have used an accelerometer as a criterion ${ }^{(62-64)}$ and some others used combined HRM with motion sensors, e.g. pedometers or accelerometers ${ }^{(65,66)}$; indeed, it is assumed that combining HR data with motion sensors may provide more valid representation of PA, but several studies have investigated the validity of self-report questionnaires by using the same type of methods as used in the present study ${ }^{(16,36,57,67,68)}$. Furthermore, the percentage HRR is assumed to give a reasonably accurate estimation of the TEE estimated by the gold standard methods of doubly labelled water $^{(44,69)}$ and from oxygen uptake measured in a laboratory or from Caltrac ${ }^{(70)}$. It is nevertheless recognized that the doubly labelled water technique is the most accurate for the estimation of daily $\mathrm{EE}$ and hence as the reference method to check the validity of questionnaires designed to evaluate the PA level ${ }^{(53)}$. But, its application is constrained by cost and technical complexity.

\section{Conclusion}

In Tunisia, in the context of the nutrition transition and the increasing burden of overweight and obesity resulting from specificities of that critical period of life, adolescents are especially prone to the related changes in diet and PA. In the present study we have developed a comprehensive and detailed PAFQ specific to Tunisian preadolescents and adolescents. This questionnaire was validated $v$. two reference methods and shown to be reproducible. The developed frequency questionnaire could be useful for large-scale description, analysis and surveillance of patterns of PA or evaluation of interventions to promote PA among Tunisian adolescents ${ }^{(71,72)}$.

\section{Acknowledgements}

Source of funding: This study was financed by the CORUS programme of the French Ministry of Overseas and
European Affairs, as part of the 'Obe-Maghreb' research project (Contract Corus 6028-2); the Institut de Recherche pour le Développement (IRD), France; and the National Institute of Nutrition and Food Technology (INNTA), Tunisia. CORUS programme, IRD and INNTA had no role in the design, analysis or writing of this article. Conflicts of interest: The authors declare they have nonfinancial competing interests. Authors' contributions: All authors participated in the study conception; collection, analysis and interpretation of the data; and writing of the manuscript.

\section{Supplementary material}

To view supplementary material for this article, please visit http://dx.doi.org/10.1017/\$1368980013002759

\section{References}

1. Cole TJ, Bellizzi MC, Flegal KM et al. (2000) Establishing a standard definition for child overweight and obesity worldwide: international survey. BMJ 320, 1240-1243.

2. Lobstein T, Baur L \& Uauy R (2004) Obesity in children and young people: a crisis in public health. Obes Rev $\mathbf{5}$, Suppl. 1, 4-104.

3. Adelman RD, Restaino IG, Alon US et al. (2001) Proteinuria and focal segmental glomerulosclerosis in severely obese adolescents. J Pediatr 138, 481-485.

4. Amin R \& Daniels S (2002) Relationship between obesity and sleep-disordered breathing in children: is it a closed loop? J Pediatr 140, 641-643.

5. Nathan BM \& Moran A (2008) Metabolic complications of obesity in childhood and adolescence: more than just diabetes. Curr Opin Endocrinol Diabetes Obes 15, 21-29.

6. Sinha R, Fisch G, Teague B et al. (2002) Prevalence of impaired glucose tolerance among children and adolescents with marked obesity. $N$ Engl J Med 346, 802-810.

7. Aounallah-Skhiri $\mathrm{H}$, Ben Romdhane $\mathrm{H}$, Traissac $\mathrm{P}$ et al. (2008) Nutritional status of Tunisian adolescents: associated gender, environmental and socio-economic factors. Public Health Nutr 11, 1306-1317.

8. Aounallah-Skhiri H, El Ati J, Traissac P et al. (2012) Blood pressure and associated factors in a North African adolescent population. A national cross-sectional study in Tunisia. BMC Public Health 12, 98.

9. World Health Organization (2010) Global Recommendations on Physical Activity for Health. Geneva: WHO.

10. Andersen LB, Harro M, Sardinha LB et al. (2006) Physical activity and clustered cardiovascular risk in children: a cross-sectional study (The European Youth Heart Study). Lancet 368, 299-304.

11. Boreham C \& Riddoch C (2001) The physical activity, fitness and health of children. J Sports Sci 19, 915-929.

12. Strong WB, Malina RM, Blimkie CJ et al. (2005) Evidence based physical activity for school-age youth. J Pediatr 146, 732-737.

13. Telama R, Yang X, Laakso L et al. (1997) Physical activity in childhood and adolescence as predictor of physical activity in young adulthood. Am J Prev Med 13, 317-323.

14. Twisk JW, Kemper HC \& van Mechelen W (2002) Prediction of cardiovascular disease risk factors later in life by physical activity and physical fitness in youth: general comments and conclusions. Int J Sports Med 23, Suppl. 1, S44-S49.

15. Aounallah-Skhiri H, Traissac P, El Ati J et al. (2011) Nutrition transition among adolescents of a south-Mediterranean 
country: dietary patterns, association with socioeconomic factors, overweight and blood pressure. A cross-sectional study in Tunisia. Nutr J 10, 38.

16. Valanou E, Bamia C \& Trichopoulou A (2006) Methodology of physical-activity and energy-expenditure assessment: a review. J Public Health 14, 58-65.

17. Pate RR (1995) Physical activity and health: dose-response issues. Res Q Exerc Sport 66, 313-317.

18. Pate RR, Pratt M, Blair SN et al. (1995) Physical activity and public health. A recommendation from the Centers for Disease Control and Prevention and the American College of Sports Medicine. JAMA 273, 402-407.

19. Kurpad AV, Raj R, Maruthy KN et al. (2006) A simple method of measuring total daily energy expenditure and physical activity level from the heart rate in adult men. Eur J Clin Nutr 60, 32-40.

20. Wicks JR, Oldridge NB, Nielsen LK et al. (2011) HT index a simple method for the prediction of oxygen uptake. Med Sci Sports Exerc 43, 2005-2012.

21. Staten LK, Taren DL, Howell WH et al. (2001) Validation of the Arizona Activity Frequency Questionnaire using doubly labeled water. Med Sci Sports Exerc 33, 1959-1967.

22. Dong L, Block G \& Mandel S (2004) Activities contributing to total energy expenditure in the United States: results from the NHAPS Study. Int J Behav Nutr Phys Act 1, 4 .

23. Trost SG (2005) Discussion Paper for the Development of Recommendations for Children's and Youths' Participation in Health Promoting Physical Activity. Canberra: Australian Department of Health and Ageing.

24. Tesfaye F, Byass P \& Wall S (2008) Concurrent comparison of energy intake and expenditure among adults in Butajira District, Ethiopia. Public Health Nutr 11, 675-683.

25. Block G, Jensen CD, Block TJ et al. (2009) The Work and Home Activities Questionnaire: energy expenditure estimates and association with percent body fat. J Phys Act Health 6, Suppl. 1, S61-S69.

26. van der Ploeg HP, Merom D, Chau JY et al. (2010) Advances in population surveillance for physical activity and sedentary behavior: reliability and validity of time use surveys. Am J Epidemiol 172, 1199-1206.

27. Gordon-Larsen P, McMurray RG \& Popkin BM (2000) Determinants of adolescent physical activity and inactivity patterns. Pediatrics 105, E83.

28. Yore MM, Ham SA, Ainsworth BE et al. (2007) Reliability and validity of the instrument used in BRFSS to assess physical activity. Med Sci Sports Exerc 39, 1267-1274.

29. Craig CL, Marshall AL, Sjostrom M et al. (2003) International physical activity questionnaire: 12-country reliability and validity. Med Sci Sports Exerc 35, 1381-1395.

30. Al-Hazzaa HM, Al-Sobayel HI \& Musaiger AO (2011) Convergent validity of the Arab Teens Lifestyle Study (ATLS) physical activity questionnaire. Int J Environ Res Public Health 8, 3810-3820.

31. Kohl HW, Fulton JE \& Caspersen CJ (2000) Assessment of physical activity among children and adolescents: a review and synthesis. Prev Med 31, issue 2, S54-S76.

32. Moore JB, Hanes JC Jr, Barbeau P et al. (2007) Validation of the Physical Activity Questionnaire for Older Children in children of different races. Pediatr Exerc Sci 19, 6-19.

33. Willett W \& Lenart E (1998) Reproducibility and validity of food-frequency questionnaires. In Nutritional Epidemiology, 2nd ed., pp. 101-147 [W Willett, editor]. New York: Oxford University Press.

34. Lohman T, Roche A \& Martorell R (1988) Anthropometric Standardization Reference Manual. Champaign, IL: Human Kinetics.

35. Cale L (1994) Self-report measures of children's physical activity: recommendations for future development and a new alternative measure. Health Educ J 53, 439-453.
36. Ridley K, Ainsworth BE \& Olds TS (2008) Development of a compendium of energy expenditures for youth. Int J Behav Nutr Phys Act 5, 45.

37. Ainsworth BE, Haskell WL, Whitt MC et al. (2000) Compendium of physical activities: an update of activity codes and MET intensities. Med Sci Sports Exerc 32, 9 Suppl., S498-S504.

38. Bernstein M, Sloutskis D, Kumanyika S et al. (1998) Data-based approach for developing a physical activity frequency questionnaire. Am J Epidemiol 147, 147-154.

39. Schofield WN (1985) Predicting basal metabolic rate, new standards and review of previous work. Hum Nutr Clin Nutr 39, Suppl. 1, 5-41.

40. Rodriguez G, Moreno LA, Sarria A et al. (2002) Resting energy expenditure in children and adolescents: agreement between calorimetry and prediction equations. Clin Nutr 21, 255-260.

41. Centers for Disease Control and Prevention (2005) Physical Activity for Everyone: Measuring Physical Intensity Activity: Metabolic Equivalent (MET) Level. Atlanta, GA: CDC.

42. Pate R, Blair SN, Eddy DO et al. (1991) ACSM's Guidelines for Exercise Testing and Prescription, 4th ed. Philadelphia, PA: Lea \& Febiger.

43. Pate RR (1993) Physical activity assessment in children and adolescents. Crit Rev Food Sci Nutr 33, 321-326.

44. Spurr GB, Prentice AM, Murgatroyd PR et al. (1988) Energy expenditure from minute-by-minute heart-rate recording: comparison with indirect calorimetry. Am J Clin Nutr $\mathbf{4 8}$, 552-559.

45. Welk GJ \& Corbin CB (1995) The validity of the Tritrac-R3D Activity Monitor for the assessment of physical activity in children. Res Q Exerc Sport 66, 202-209.

46. Leger LA \& Lambert J (1982) A maximal multistage 20-m shuttle run test to predict $\mathrm{VO}_{2}$ max. Eur J Appl Physiol Occup Physiol 49, 1-12.

47. Karvonen MJ, Kentala E \& Mustala O (1957) The effects of training on heart rate; a longitudinal study. Ann Med Exp Fenn 35, 307-315.

48. Schutz Y, Weinsier RL \& Hunter GR (2001) Assessment of free-living physical activity in humans: an overview of currently available and proposed new measures. Obes Res 9, 368-379.

49. Anderson MA, Dewey KG, Frongillo E et al. (1995) An evaluation of infant growth - the use and interpretation of anthropometry in infants. Bull World Health Organ 73, 165-174.

50. Tudor-Locke C, Ainsworth BE, Adair LS et al. (2003) Physical activity in Filipino youth: the Cebu Longitudinal Health and Nutrition Survey. Int J Obes Relat Metab Disord 27, 181-190.

51. Bland JM \& Altman DG (1986) Statistical methods for assessing agreement between two methods of clinical measurement. Lancet 1, 307-310.

52. Landis JR \& Koch GG (1977) The measurement of observer agreement for categorical data. Biometrics 33, 159-174.

53. Montoye HJ, Kemper HCG, Saris WHM et al. (1996) Measuring Physical Activity and Energy Expenditure, 1st ed. Champaign, IL: Human Kinetics.

54. Livingstone MB (1997) Heart-rate monitoring: the answer for assessing energy expenditure and physical activity in population studies? Br J Nutr 78, 869-871.

55. Weston AT, Petosa R \& Pate RR (1997) Validation of an instrument for measurement of physical activity in youth. Med Sci Sports Exerc 29, 138-143.

56. Baranowski T, Dworkin RJ, Cieslik CJ et al. (1984) Reliability and validity of self report of aerobic activity family health project. Res Q Exerc Sport 55, 309-317.

57. Sallis JF, Buono MJ, Roby JJ et al. (1993) Seven-day recall and other physical activity self-reports in children and adolescents. Med Sci Sports Exerc 25, 99-108. 
58. Popkin BM, Adair LS \& Ng SW (2012) Global nutrition transition and the pandemic of obesity in developing countries. Nutr Rev 70, 3-21.

59. Matthews CE, Moore SC, George SM et al. (2012) Improving self-reports of active and sedentary behaviors in large epidemiologic studies. Exerc Sport Sci Rev 40, 118-126.

60. Maas S, Kok ML, Westra HG et al. (1989) The validity of the use of heart rate in estimating oxygen consumption in static and in combined static/dynamic exercise. Ergonomics 32, 141-148.

61. Maffeis C, Pinelli L, Zaffanello M et al. (1995) Daily energy expenditure in free-living conditions in obese and nonobese children: comparison of doubly labelled water $\left(2 \mathrm{H}_{2}{ }^{18} \mathrm{O}\right)$ method and heart-rate monitoring. Int $J$ Obes Relat Metab Disord 19, 671-677.

62. Corder K, Ekelund U, Steele RM et al. (2008) Assessment of physical activity in youth. J Appl Physiol 105, 977-987.

63. Philippaerts RM, Matton L, Wijndaele K et al. (2006) Validity of a physical activity computer questionnaire in 12- to 18-year-old boys and girls. Int J Sports Med 27, 131-136.

64. Telford A, Salmon J, Jolley D et al. (2004) Reliability and validity of physical activity questionnaires for children: The Children's Leisure Activities Study Survey (CLASS). Pediatr Exerc Sci 16, 64-78.

65. Bassett DR Jr, Ainsworth BE, Swartz AM et al. (2000) Validity of four motion sensors in measuring moderate intensity physical activity. Med Sci Sports Exerc 32, 9 Suppl., S471-S480.
66. Sobngwi E, Mbanya JC, Unwin NC et al. (2001) Development and validation of a questionnaire for the assessment of physical activity in epidemiological studies in Sub-Saharan Africa. Int J Epidemiol 30, 1361-1368.

67. Booth ML, Okely AD, Chey T et al. (2001) The reliability and validity of the physical activity questions in the WHO health behaviour in schoolchildren (HBSC) survey: a population study. Br J Sports Med 35, 263-267.

68. Florindo AA, Romero A, Peres SV et al. (2006) Development and validation of a physical activity assessment questionnaire for adolescents. Rev Saude Publica 40, 802-809.

69. Van den Berg-Emons RJ, Saris WH, Westerterp KR et al. (1996) Heart rate monitoring to assess energy expenditure in children with reduced physical activity. Med Sci Sports Exerc 28, 496-501.

70. Ballor DL, Burke LM, Knudson DV et al. (1989) Comparison of three methods of estimating energy expenditure: Caltrac, heart rate, and video analysis. Res $Q$ Exerc Sport 60, 362-368.

71. Harrabi I, Maatoug J, Gaha M et al. (2010) School-based intervention to promote healthy lifestyles in Sousse, Tunisia. Indian J Community Med 35, 94-99.

72. Holdsworth I, El Ati J, Bour A et al. (2012) Developing national obesity policy in middle-income countries: a case study from North Africa. Health Policy Plan (Epublication ahead of print version). 